\title{
Risks of dependence on benzodiazepine drugs: a major problem of long term treatment
}

\author{
Heather Ashton
}

Phlegmatic people dislike taking benzodiazepine drugs. In those with low anxiety traits benzodiazepines are dysphoric and may paradoxically increase anxiety. ${ }^{1}$ In normal subjects benzodiazepines improve performance under experimental stress but worsen it under conditions of low stress. ${ }^{2}$ Benzodiazepines relieve preoperative anxiety in patients with high anticipatory anxiety but not in those with low anticipatory anxiety. Thus like $\beta$ receptor blocking agents benzodiazepines require some underlying tone upon which to exert their anxiolytic effects. In general, the greater the anxiety the greater the anxiolytic efficacy.

It follows that most people who take benzodiazepines are anxious. In students a history of prescribed benzodiazepines correlates with a high anxiety trait. ${ }^{4}$ Long term users likewise have high scores for neuroticism. ${ }^{56}$ These findings apply when benzodiazepines are used both as anxiolytic and as hypnotic agents. Thus people who take and keep on taking benzodiazepines are a self selected population with high anxiety traits or states.

\section{Reasons for dependence on benzodiazepines}

Dependence on benzodiazepines in the sense that users require the drugs for psychological comfort and suffer withdrawal symptoms when they stop taking them develops rapidly. ${ }^{7}$ The same patients who find benzodiazepines efficacious are also prone to dependence and to withdrawal effects, which are themselves largely manifestations of anxiety.

This vulnerability occurs for several reasons. Firstly, anxious people are more likely to complain of symptoms. ${ }^{8}$ Secondly, long term users of benzodiazepines tend to have poor abilities in coping with stress. The pharmacological basis for both anxiety and a poor ability to cope with stress may be low activity in limbic system pathways utilising $\gamma$-aminobutyric acid ${ }^{9}$ or high activity in those utilising serotonin, ${ }^{10}$. or both. Such activity is counteracted by benzodiazepines. ${ }^{10}$ Benzodiazepines, however, impair learning of strategies to cope with stress, such as behavioural treatment for agoraphobia. ${ }^{5112}$ Other characteristics (passive-dependent personality, resourcelessness ${ }^{713}$ ) also increase the vulnerability to withdrawal symptoms and the motivation for continued use. Benzodiazepine deprivation in such users leaves them unprotected from stress and re-exposes their limitations of coping.

Finally, anxious people may be innately sensitive to punishing stimuli. ${ }^{14}$ Benzodiazepines are "depunishing" drugs. Even in animals they protect against punishing stimuli ${ }^{15}$ and are taken therapeutically by many people as protective drugs. ${ }^{6}$ In contrast, those who take benzodiazepines at high doses for kicks ${ }^{16}$ form a different population, innately less sensitive to punishment ${ }^{14}$ that also tends to abuse other drugs ${ }^{4}$ (see box).

\section{Clinical \\ Psychopharmacology Unit, Medical School, Newcastle upon Tyne NE2 4HH Heather Ashton, FRCP, reader in clinical psychopharmacology}

\section{Withdrawal syndrome with benzodiazepines}

The overall incidence of a withdrawal syndrome after long term therapeutic doses of benzodiazepines is unknown. Estimates vary with the population studied, the duration of drug use, the rate of withdrawal, the length of follow up, and the definition. Lader and colleagues reported a $100 \%$ incidence: all patients experienced withdrawal symptoms (increased anxiety,

\section{Profiles of dependence on drugs}

People who become dependent on drugs are suggested to be two different populations at the extremes of a normal distribution. Those who take drugs for protection are anxious, have high scores for neuroticism $(\mathrm{N}){ }^{+6}{ }^{17}$ are highly susceptible to punishment, ${ }^{14}$ tender minded, and socially compliant. ${ }^{+}$Their preferred drugs are benzodiazepine tranquillosedatives, which they tend to take long term in low, prescribed doses. They are sensitive to withdrawal largely because of their anxiety and poor abilities in coping with stress.

In contrast, those who take drugs for kicks have high scores for psychoticism $(\mathrm{P}),{ }^{17}$ are highly sensitive to reward, ${ }^{14}$ impulsive, tough minded, antisocial, and seek sensation. ${ }^{+17}$ They tend to abuse hard and soft drugs, often illicitly, ${ }^{+1 / i}$ which they take intermittently or long term in high doses. They experience an abstinence syndrome largely because of the high doses used.

The general population, which is less dependent on drugs, occupies the middle of the curve. Nicotine and alcohol (which have both tranquillising and directly rewarding properties over a moderate range of doses ${ }^{30}$ ) cover the whole spectrum - a fact which probably explains their widespread use.

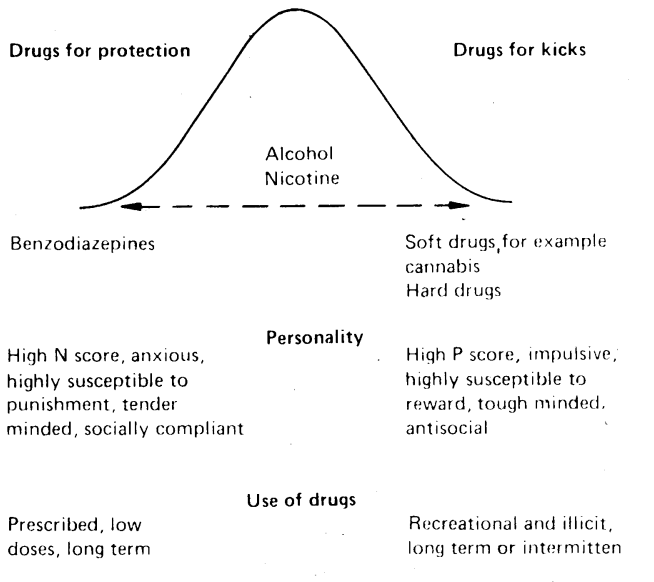

other psychological and somatic symptoms, and perceptual disturbances), ${ }^{1819}$ although slow withdrawal minimises symptoms. ${ }^{20}$ Tyrer et al estimated that only $30-45 \%$ experienced true withdrawal symptoms, defined as a temporary increase in anxiety to half or more above prewithdrawal values or the development of two or more new symptoms ("pseudowithdrawal" occurred in some patients who thought that they were withdrawing. $)^{1321}$ Others report similar results. ${ }^{162223}$

Withdrawal criteria based on differences from prewithdrawal measures, however, underestimate the true incidence. I have observed that long term users of benzodiazepines develop further symptoms while taking the drugs. ${ }^{51 t}$ These include increasing anxiety and also paraesthesiae and perceptual disturbances, new symptoms generally associated with withdrawal. ${ }^{18}$ These symptoms may result from tolerance to some effects of benzodiazepines so that a withdrawal syndrome emerges despite continued drug use. Supporting this observation is the fact that increasing the dose of benzodiazepines temporarily alleviates symptoms. A large escalation in dose is reputedly rare $^{7}$ no doubt 
Controversies in

\section{Therapeutics}

because benzodiazepines are medically prescribed to patients who are generally compliant. Nevertheless, $7 \cdot 5-10 \cdot 0 \mathrm{mg}$ lorazepam daily ${ }^{11}$ is not uncommon (equivalent to $75-100 \mathrm{mg}$ diazepam ${ }^{24}$ ).

Withdrawal symptoms occurring during long term use are more noticeable with potent benzodiazepines that are rapidly eliminated. Patients taking lorazepam ${ }^{5}$ or alprazolam ${ }^{25}$ commonly experience craving or dysphoria between doses, and daytime withdrawal effects from the use of triazolam as a hypnotic are well recognised." Thus the motivation to use benzodiazepines for anxiolysis or hypnosis gradually merges with the need to avoid withdrawal effects. For this reason it may be impossible to measure withdrawal effects precisely.

Recently Murphy et al broadened their withdrawal criteria to include a temporary increase in anxiety to less than initial values. ${ }^{26}$ In this study ratings before benzodiazepine were available and the incidence of withdrawal symptoms was again $30 \%$. Diazepam was, however, given for only six weeks and the results may not apply to those who use it for longer. Furthermore, many long term users (46 out of 86 in one study ${ }^{27}$ ) decline to undertake withdrawal and many drop out ( 18 of the remaining $40^{27}$ ) because of fear or experience of withdrawal. Taking account of these subjects would substantially raise the apparent incidence.

\section{Pharmacological mechanisms}

The pharmacodynamic mechanism of benzodiazepine tolerance and dependence is probably homoeostatic down regulation of $\gamma$-aminobutyric acid and benzodiazepine receptors in the limbic system. ${ }^{28}$ Once this has occurred, withdrawal of the drug results in a state of underactivity of pathways utilising $\gamma$-aminobutyric acid with a pattern of unapposed neuronal excitation characteristic of benzodiazepine withdrawal ${ }^{29}$ and anxiety states. $^{10}$ Similar brain mechanisms mediate the psychological and somatic symptoms of both conditions, which are in many respects inseparable.

Lader notes that even non-anxious people may develop benzodiazepine withdrawal symptoms, ${ }^{20}$ although they may be less prone to do so.? There may be a population of stable people who discard benzodiazepines without difficulty when a temporary stress has passed. I suggest, however, that most people who continue to use benzodiazepines are dependent on the drugs for enhancement of the effects of $\gamma$-aminobutyric acid. All will suffer withdrawal symptoms unless they withdraw slowly and simultaneously learn alternative strategies of coping. Long term control of anxiety probably requires learned changes in endogenous $\gamma$-aminobutyric acid transmission rather than the imposition of an exogenous cover up with benzodiazepines.

1 Parrott AC, Kentridge R. Personal constructs of anxiety under the 1,5 benzodiazepine clobazam related to trait-anxiety levels of the personality. Psychopharmacology 1982;75:353-7.

2 Parrott AC, Davies S. Effects of a 1,5 benzodiazepine upon performance in an experimental stress situation. Psychopharmacology 1983;79:367-9.

3.O'Boyle CA, Harris D, Barry H, Cullen JH. Differential effects of benzodiazepine sedation in high and low anxious patients in 'real life' stress setting. Psychopharmacology 1986;88:266-9.

4 Golding JF, Cornish AM. Personality and life-style in medical students: psychopharmacological aspects. Psychology and Health 1987;1:287-301.

5 Ashton H. Benzodiazepine withdrawal: an unfinished story. Br Med $\mathcal{f}$ 1984;288:1135-40.
Ashton H. Benzodian

6 Ashton H, Golding JF. Tranquillisers: prevalence and possible consequences: data from a large United Kingdom survey. Br $\mathcal{f}$ Addict (in press)

7 Murphy SB, Tyrer P. The essence of benzodiazepine dependence. In: Lader $\mathrm{M}$, ed. The psychopharmacology of addiction. Oxford: Oxford University Press, 1988:157-67.

8 Bond MR. Personality and pain. In: Lipton S, ed. Persistent pain: modern methods of treatment. Vol 2. London: Academic Press, 1980:1-26.

9 Leonard BE. New antidepressants and the biology of depression. Stress Medicine 1985;1:9-16.

10 Gray JA. The neuropsychology of anxiety. Oxford: Clarendon Press, 1982.

11 Ashton $\mathrm{H}$. Benzodiazepine withdrawal: outcome in 50 patients. $\mathrm{Br} \mathcal{F}$ Addict $1987 ; 82: 665-71$.

12 Gray JA. Interactions between drugs and behaviour therapy. In: Eysenk HJ, Martin I, eds. Theoretical foundations of behaviour therapy. New York: Plenum Press, 1987:433-47.

13 Tyrer $P$, Owen $R$, Dawling S. Gradual withdrawal of diazepam after long-term therapy. Lancet 1983;i:1402-6.

14 Gray JA. The neuropsychology of emotion and personality. In: Stahl SM Iverson SD, Goodman EC, eds. Cognitive neurochemistry. Oxford: Oxford University Press, 1987:171-90.

15 Iverson SD, Iverson LL. Behavioural pharmacology. New York: Oxford University Press, 1981.

16 Woods JH, Katz JL, Winger G. Abuse liability of benzodiazepines. Pharmacol Rev 1987;39:251-419.

17 Eysenck HJ, Eysenck SBG. Manual of the Eysenck personality questionnaire Essex: Hodder and Stoughton, 1975.

18 Petursson $\mathrm{H}$, Lader $\mathrm{MH}$. Withdrawal from long-term benzodiazepine treatment. Br Med f 1981;283:643-5.

19 Lader $\mathrm{MH}$, Olajide D. A comparison of buspirone and placebo in relieving benzodiazepine withdrawal symptoms. F Clin Psychopharmacol 1987;7: 11-5.

20 Lader M, ed. The psychopharmacology of addiction. Oxford: Oxford University Press, 1988:1-14.

21 Tyrer P, Rutherford D, Huggett T. Benzodiazepine withdrawal symptoms and propranolol. Lancet 1981;i:520-2.

22 Rickels K, Case WG, Downing RW, Winokur A. Long-term diazepam therapy and clinical outcome. $\mathscr{F} A M A$ 1983;250:767-71.

23 Busto U, Sellers EM, Naranjo CA, Cappell HP, Sanchez CM, Sykora K. Withdrawal reaction after long-term therapeutic use of benzodiazepines. N Engl F Med 1986;315:654-9.

4 Northern Regional Health Authority. Benzodiazepine dependence and withdrawal - an update. Drug Newsletter 1985;31:125-8.

25 Hermann JB, Brotman AW, Rosenbaum JF. Rebound anxiety in panic disorder patients treated with shorter-acting benzodiazepines. $\mathcal{f}$ Clin Psychiatry 1987;48(suppl 10):22-8.

26 Murphy SM, Owen R, Tyrer P. Comparative assessment of efficacy and withdrawal symptoms after six and twelve weeks treatment with diazepam or buspirone Brf Psychiorn (in press).

27 Tyrer P. Round table discussion. In: Costa E, ed. The benzodiazepines: from molecular biology to clinical practice. New York: Raven Press, 1983:400-6.

28 Nutt D. Benzodiazepine dependence in the clinic: reason for anxiety? Trends in Neurosciences 1986;9:547-60.

29 Cowen PJ. Psychotropic drugs and human 5-HT neuroendocrinology. Trends in Pharmacological Sciences 1987;8:105-8.

30 Ashton H. Brain systems, disorders, and psychotropic drugs. Oxford: Oxford University Press, 1987.
Peter Tyrer

continued from page 102 is excluded the features associated with dependencehigh dosage, long duration of treatment, and previous dependence on psychotropic drugs - are avoided and the prescription becomes short term, low dosage, and comparatively free of risk (table). Doctors need to realise that benzodiazepines now have no value in long

Influence of premorbid personality on factors predisposing to dependence on benzodiazepines

\begin{tabular}{|c|c|c|}
\hline \multirow[b]{2}{*}{ Risk factor } & \multicolumn{2}{|c|}{ Type of premorbid personality } \\
\hline & Normal & Dependent \\
\hline Dose & Low & Variable \\
\hline Frequency & Intermittent & Regular \\
\hline Duration of treatment & Short & Long \\
\hline $\begin{array}{l}\text { Previous dependence on prescribed } \\
\text { psvchotropic drugs }\end{array}$ & Rare & Common \\
\hline Nature of benzodiazepine & $\begin{array}{l}\text { Determined by } \\
\text { prescriber }\end{array}$ & $\begin{array}{l}\text { Determined } \\
\text { by prescriber }\end{array}$ \\
\hline
\end{tabular}

term prescribing. These drugs should not be given for longer than four weeks; if given for longer they are less effective than antidepressants and psychological procedures such as cognitive therapy and self help packages. ${ }^{13}$ They should be confined to short term intervention when rapid relief of anxiety and insomnia is considered to be essential. In making the decision to prescribe benzodiazepines doctors need to diagnose symptoms, circumstances, and person. If they do this successfully they have no reason to fear dependence.

1 Murphy SM, Tyrer P. The essence of benzodiazepine dependence. In: Lader $\mathrm{M}$, ed. The psychopharmacology of addiction. Oxford: Oxford University Press, 1988;157-67.

2 Petursson $\mathrm{H}$, Lader $\mathrm{MH}$. Withdrawal from long-term benzodiazepine treatment. Br Med F 1981;283:643-5.

3 Ashton $\mathrm{H}$. Benzodiazepine withdrawal: an unfinished story. $\mathrm{Br}$ Med $\mathrm{f}$ 1984;288:1135-40.

4 Busto U, Sellers EM, Naranjo CA, Cappell H, Sanchez-Craig M, Sykora K. Withdrawal reaction after long-term therapeutic use of benzodiazepines. $N$ Engl f Med 1986;315:854-9. 